\title{
Numerical Simulation of Geostress and Pore Pressure Evolution around Oil or Water Well under Different Injection-Production Ratio
}

\author{
Liu Jian-jun, ${ }^{1,2}$ Yu Xian-bin, ${ }^{2}$ and Zhao Jin-zhou ${ }^{1}$ \\ ${ }^{1}$ State Key Laboratory of Oil and Gas Reservoir Geology and Exploitation, Southwest Petroleum University, Chengdu, \\ Sichuan 610500, China \\ ${ }^{2}$ School of Civil Engineering and Architecture, Southwest Petroleum University, Chengdu, Sichuan 610500, China
}

Correspondence should be addressed to Yu Xian-bin; yuxianbin2006@126.com

Received 16 September 2012; Revised 25 January 2013; Accepted 25 January 2013

Academic Editor: Diego J. Celentano

Copyright (C) 2013 Liu Jian-jun et al. This is an open access article distributed under the Creative Commons Attribution License, which permits unrestricted use, distribution, and reproduction in any medium, provided the original work is properly cited.

\begin{abstract}
Geostress evolution in the process of oil field development can directly influence wellbore stability. Therefore, it is significant to strengthen the research of the evolution rule for well drilling and casing protection. Considering the interaction between reservoir seepage and stress fields, a mathematical model to characterize the stress evolution around wellbore was built. Using the FEM Software ABAQUS, through numerical simulation, the authors studied the evolution features of pore pressure and stress changes with time under different injection-production ratio, which disclosed the dynamic change regulation of pore pressure and stress of surrounding rock nearby the injection and production wells. These results may have implications in the treatment of wellbore stability and optimizing the injection and production processes during oil and gas production.
\end{abstract}

\section{Introduction}

Geostress is often related to the instability of wellbore during drilling process, the damage of water channeling and flooding, and the shortage of anhydrous production period due to well pattern locations in water injection process. Because of the effect of many factors, the change of geostress field is complex, and a lot of research work has been done by scholars in petroleum engineering field. From the 1970s, Schlumberger logging company began to research and apply logging information to account for strata mechanics problems and explained the problems of petroleum engineering, such as the formation failure pressure and stratum collapsed pressure, with sanding formation. In 1987, United States Department of Energy carried through fracture tests with changing stress in multiwell test. Two adjacent wells were being constructed at the same time, and it was obvious to test out the stress field changing by the impact of adjacent wells fracture $[1,2]$. Johnson and Rodgerson theoretically derived the calculation formula of the stress field around the crack in infinite elasticity [3]. Warplnskl and Branagan researched pore pressure around the previous crack evolved with time. Furthermore, they pointed out that long-term production could gradually change the stress field, which made stress occur $90^{\circ}$ reverse [4]. Yan Shuwen carried out earlier the research work that used log information to interpret geostress parameters. Huang Rongzun carried out the research work such as the formation fracture pressure and collapse pressure for the research of stability of wellbore. Liu et al. established fluidsolid coupling theory model of the fractural low permeability reservoir with considering reservoir stress sensitivity and gave reservoir stress field evolution with taking porosity and permeability characteristics changing into account [5]. Fan et al. researched the impact of the oil and gas well production on geostress; however, his research did not consider the influence of the permeability anisotropy on stress change [6]. Yin et al. used finite element method to simulate the borehole wall rock stress field and the pressure field evolution 
in the relief process [7]. Wang Dongmei, based on rock mechanics analysis, established the three formation pressure (formation pore pressure, formation fracture pressure, and formation collapse pressure) calculation models, according to Mohr-Coulomb criterion and tensile failure criterion [8]. Xiu et al. used relevant theoretical approach to deduce the theoretical formula of the stratigraphic level to stress with pore pressure evolution [9]. These studies play an important role in promoting the research work of the stress field, but the focus of the studies is the reservoir and the stress field variation of borehole wall rock to be further deepened.

\section{The Mathematics-Mechanical Model of Stress Analysis of Sidewall Surrounding Rock}

In oil field development, water injection and recovery operation will result in seepage field changing, which not only can make the reservoir rock mass's physical and mechanical parameters change, but can make also reservoir effective stress change and then lead the near well stress to change, which brings about the change of the combination for casingcement ring-surrounding rock stress states [10]. Because of this, we establish the following mathematical-mechanical model.

2.1. The Mathematical Model of Seepage Field on the Basis of Fluid-Solid Coupling Theory. Considering injection and recovery, assume that the fluid can be compressed and the system of cement ring and the surrounding rock is considered a deformable porous media, so the mathematical model of single-phase fluid flow in the deformed media reservoir is as the following [11]:

$$
\frac{\rho K}{\eta} \nabla^{2} p+\phi \rho_{0} C_{f} \frac{\partial p}{\partial t}+\frac{\rho\left(1-\phi_{0}\right)}{\left(1+\varepsilon_{V}\right)^{2}} \frac{\partial \varepsilon_{V}}{\partial t}+q=0,
$$

where $\rho$ is fluid density, $K$ is permeability of the composite system, $\phi$ is void ratio of the composite system, $C_{f}$ is the fluid compression coefficient, $p$ is fluid pressure, $t$ is the time, $\eta$ is fluid viscosity, $\rho_{0}$ is initial density of the composite system, $\phi_{0}$ is initial void ratio of the composite system, $\varepsilon_{v}=\varepsilon_{x}+\varepsilon_{y}+\varepsilon_{z}$ is the volumetric strain, and $q$ is mass flow of the injection (recovery) unit volume.

\subsection{The Mathematical Model of Stress Field on the Basis of} Fluid-Solid Coupling Theory. According to the related theory of elastic-plastic mechanics, get the mathematics model of the combination about casing-cement ring-surrounding rock stress field on the basis of the hypothesis that wall of the surrounding rock and cement ring are elastic-plastic mediums. Stress field equation has the following three group equations.

(1) Equilibrium differential equations:

$$
\sigma_{i j, j}-\left(\alpha p \delta_{i j}\right)_{, j}+X_{i}=0
$$

where $\sigma_{i j}$ is the normal or shear stress, $\alpha$ is the Biot coefficient from 0 to 1 , and $X_{i}$ is volume force.

(2) Compatibility equations:

$$
\varepsilon_{i j}=\frac{1}{2}\left(u_{i, j}+u_{j, i}\right)
$$

where $\varepsilon_{i j}$ is the normal or shear strain and $u$ is the displacement.

(3) Constitutive equations:

Incremental form of constitutive equations of surrounding rock deformation field [12]:

$$
\left\{d \sigma_{i j}^{\prime}\right\}=\left[D_{\mathrm{ep}}\right]\left\{d \varepsilon_{i j}\right\},
$$

where $d \sigma_{i j}^{\prime}$ is the effective stress increment, and $\left[D_{\mathrm{ep}}\right]$ is the elastic-plastic matrix.

2.3. The Coupling Relationship between Seepage Field and Stress Field. The relationship among porosity, permeability, and volumetric strain of reservoir rock can be used by the following formula [13]:

$$
k=k_{0}\left[\left(\frac{1}{\phi_{0}}\right)\left(1+\varepsilon_{v}\right)^{3}-\left(\frac{1-\phi_{0}}{\phi_{0}}\right)\left(1+\varepsilon_{v}\right)^{-(1 / 3)}\right]^{3},
$$

where $k_{0}$ is the initial permeability coefficient of the rock mass.

The above equations constitute a mathematical model of fluid-structure interaction, and solving for a particular reservoir must also include stress, seepage boundary conditions, which include seepage boundary and initial conditions, sidewall rock stress field boundary, and initial conditions.

\subsection{Boundary and Initial Condition}

\subsubsection{Boundary and Initial Conditions of Seepage Field}

(1) Boundary Conditions. According to the related theory of fluid mechanics in porous media, we know that fluid flow boundary conditions contain constant pressure boundary and quantitative boundary. Due to the needs of the numerical simulation, we use constant pressure boundary, which is given on the boundary of unknown function. In addition, this value cannot change with time. And the expression is as the following:

$$
\left.\frac{\partial p}{\partial n}\right|_{\Gamma}=f_{p}(x, y, t)
$$

where $n$ is the normal of the boundary direction.

(2) Initial Conditions. Solving the nonstationary flow problems, in addition to the need for boundary conditions, we also need the initial conditions. The initial $(t=0)$ distribution of pore pressure in the reservoir. The expression is as the following:

$$
\left.p(x, y, z)\right|_{(x, y, z) \in \Gamma}=f_{p}(x, y, z, t),
$$

where $f_{p}(x, y, z, t)$ is the given function on the boundary when the time is $t$. 


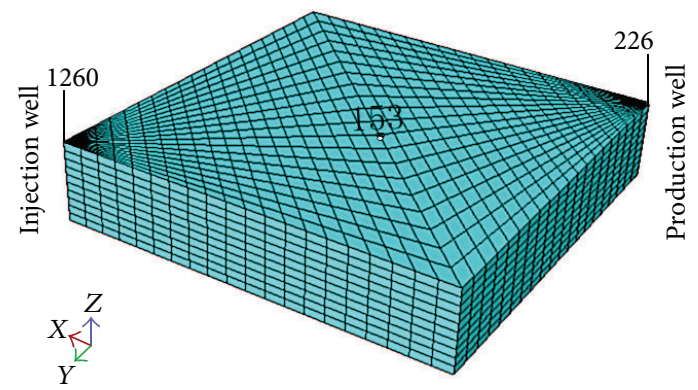

Figure 1: Computational model and meshing.

2.4.2. The Boundary and Initial Conditions of Stress Field. Stress field boundary and initial conditions are most the first boundary condition; that is, surface force of the combination system is known. The expression is as the following [14]:

$$
\sigma_{i j} L_{j}=F_{i}(x, y) \text {, }
$$

where $L_{j}$ is the directional derivative of the boundary and $F_{i}(x, y, z)$ is the surface force distribution function.

\section{Numerical Simulation of the Sidewall Surrounding Rock}

Based on fluid-structure interaction theory and using the FEM Software ABAQUS, the dynamic evolution of sidewall surrounding rock stress field with the ever-changing injection oil is carried on.

3.1. Establish Numerical Model. In order to compare the variation of pore pressure and stress field about sidewall surrounding rock of the injection well and production well, the numerical model uses an injection well and a production well. Calculation model is shown in Figure 1. Select the model located in sandstone reservoir placed $1500 \mathrm{~m}$ underground, and the reservoir thickness is $10 \mathrm{~m}$. What is more, the radius of the injection well and production wells is $0.15 \mathrm{~m}$, and well spacing between the injection and production wells is $70.7 \mathrm{~m}$. Sidewall rock mass is the elastic-plastic media and obeys the Drucker-Prager model. The mechanical parameters are shown in Table 1.

\subsection{Pretreatment Settings of Computational Model}

3.2.1. Meshing. The stress distribution of the rock mass is around the borehole due to the impact of the borehole, which is prone to stress concentration, so the grid near borehole should be refined, and the grid far away from borehole should be increased appropriately to meet the numerical simulation speed and accuracy requirements. Using hexahedral elements, the number of units is 8000 , and the number of nodes is 9471 . The mesh is shown in Figure 1.

3.2.2. Setting the Boundary and Initial Conditions. Constant boundary nonuniform stresses: geostress of the direction
$X$ takes $25 \mathrm{Mpa}$; geostress of the direction $Y$ takes $23 \mathrm{Mpa}$; and the direction $Z$ covered by rock pressure takes $30 \mathrm{Mpa}$. What is more, constraint the bottom of block. Pore pressure of the outer boundary is $14.5 \mathrm{MPa}$, and the initial pore pressure formation is also $14.5 \mathrm{MPa}$. The boundary and initial conditions are shown in Figure 2.

3.2.3. Setting Analysis Step. The first step is the balance of geostress field, and the second step is the numerical simulation of the injection well and the production well. The simulation time takes 10 years, supposing that the simulation of water injection and oil production is continuous.

3.2.4. Setting Analysis Conditions. Impose the flow boundary to the injection well and the production well, and keep the water injection rate per unit of time unchanged of injection well.

In this paper, divide into the following conditions the numerical simulation of fluid-structure interaction in accordance with the different injection-production ratio to change oil production per unit of time.

(1) Water injection rate is more than production: $1: 0$; $1: 0.5$; and $1: 0.8$.

(2) Water injection rate is equal to production: $1: 1$.

(3) Water injection rate is less than the production: $1: 1.2$, $1: 1.5$ and $1: 8$.

3.3. Analysis of Simulation Results. Keep the water injection rate per unit time constant, with increasing production per unit time of the well, respectively, giving the corresponding pore pressure contours, $Z$-displacement contours, and the change curve of several points with time of pore pressure and $Z$-displacement of block rock mass. Detailed locations of the points are shown in Figure 1.

3.3.1. Water Injection Rate Is More Than Production. In accordance with the injection-production ratio: $1: 0,1: 0.5$, and $1: 0.8$, respectively, give the final computed time of pore pressure contours, $Z$-direction displacement contours of the block, and the change curve with time about pore pressure of the three points (N1206, N2261, and N153). They are shown in Figures 3-14.

We can get the following conclusions from Figure 3. Pore pressure of the entire block rock mass of the simulation has an upward trend, and the maximum pore pressure of injection well sidewall can reach $50.88 \mathrm{MPa}$, which is $36.38 \mathrm{MPa}$ higher than the initial pore pressure of stratum. From Figure 4, we can find that the upper surface of the block rock mass of the simulation has a positive displacement in the $Z$-direction, and from Figures 5 and 6 , we also find that both pore pressure and the $Z$-direction displacement with time increasing have a continuous increasing trend.

Firstly, from Figure 7, we can find that pore pressure of the entire block of the simulation has an upward trend when the injection ratio is $1: 0.5$, and the rising magnitude of pore pressure is much larger than near the production well. What is more, from Figure 8, we can find that the upper 
TABLE 1: The mechanical parameters of the simulated zone.

\begin{tabular}{lcccccccc}
\hline Materials & $\begin{array}{c}\text { Modulus of } \\
\text { elasticity } \\
(\mathrm{MPa})\end{array}$ & $\begin{array}{c}\text { Poisson's } \\
\text { ratio } \mu\end{array}$ & $\begin{array}{c}\text { Density } \\
\left(\mathrm{kg} / \mathrm{m}^{3}\right)\end{array}$ & $\begin{array}{c}\text { Cohesion } \\
(\mathrm{MPa})\end{array}$ & $\begin{array}{c}\text { Internal } \\
\text { frictional } \\
\text { angle }\left({ }^{\circ}\right)\end{array}$ & $\begin{array}{c}\text { Dilation } \\
\text { angle }\left({ }^{\circ}\right)\end{array}$ & $\begin{array}{c}\text { Void ratio } \\
\times 100 \%\end{array}$ & $\begin{array}{c}\text { Permeability } \\
(\mathrm{md})\end{array}$ \\
\hline Rock & $2.1 \times 104$ & 0.25 & 2300 & - & 38 & 18.5 & 11.2 \\
\hline
\end{tabular}

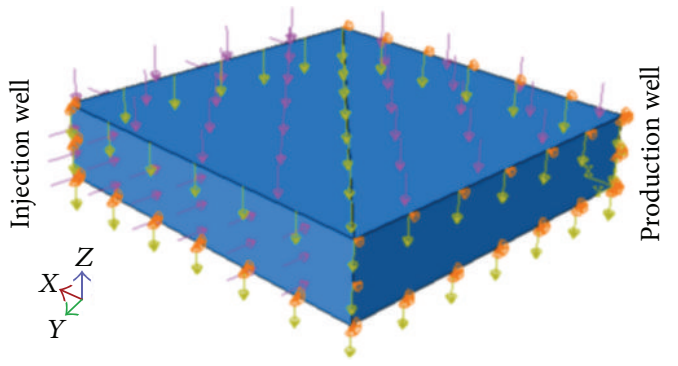

Figure 2: Boundary and initial conditions.

POR $(\mathrm{Pa})$

(Avg: $75 \%)$

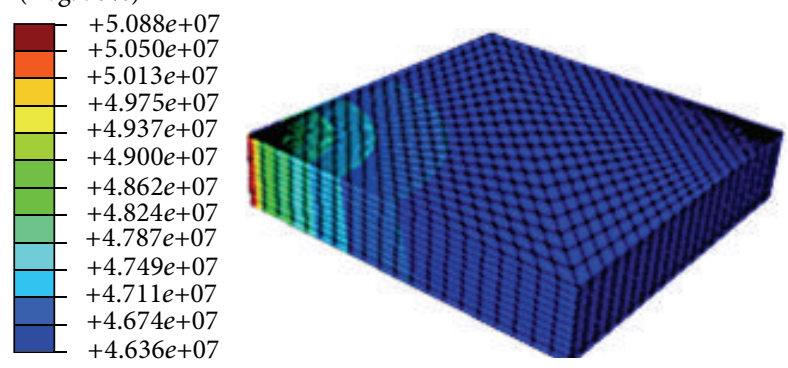

FIgURE 3: Pore pressure contours of the block when injectionproduction ratio is $1: 0$.

surface of the block rock mass of the simulation has a positive displacement in the $Z$-direction. Finally, from Figure 9, we can find that pore pressure near the injection well shows a tendency to continuously increase with time; however, pore pressure near the production well firstly decreases and then increases, and water flooding time is about the 35th day. From Figure 10, of course, it can be seen that the trend of $Z$-direction displacement changing with time is basically the same with the trend pore pressure changing with time.

Firstly, from Figure 11, we can find that pore pressure of the entire block of the simulation has an upward trend when the injection ratio is $1: 0.8$, and the rising magnitude of pore pressure is much larger than near the production well. What is more, from Figure 12, we can find that the upper surface of the block rock mass of the simulation has a positive displacement in the $Z$-direction. Finally, from Figure 13, we can find that pore pressure near the injection well shows a tendency to continuously increase with time; however, pore pressure near the production well firstly decreases and then increases, and water flooding time is about the 60th day. From Figure 14, of course, it can be seen that the trend of
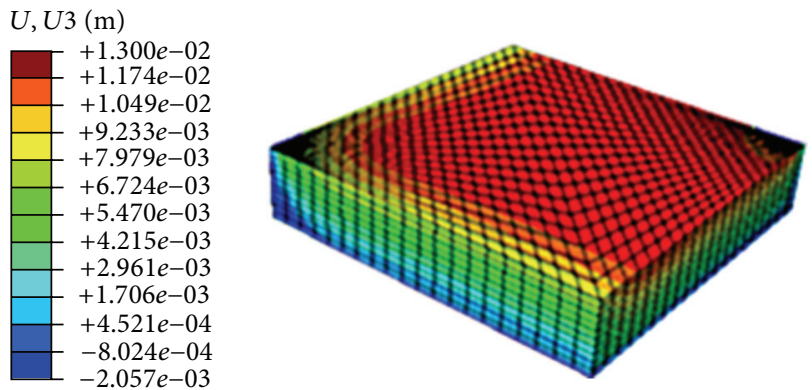

FIGURE 4: Z-direction displacement contours of block when injection-production ratio is $1: 0$.

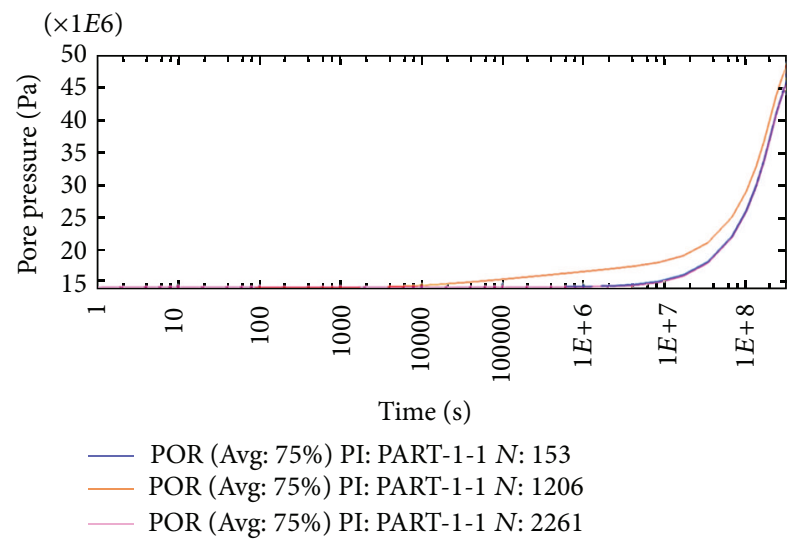

FIgURE 5: The change curve with time about pore pressure of the three points when injection-production ratio is $1: 0$.

$Z$-direction displacement changing with time is basically the same with the trend pore pressure changing with time.

Firstly, from the comparison to Figures 3, 7, and 11, it can be seen that when the water injection rate is greater than production and water injection rate is fixed, pore pressure of the entire block presents a continuous decreasing trend with the injection-production ratio increasing. Secondly, from Figures 4,8 , and 12 , we can find that the positive $Z$-direction displacement of the entire block continues to reduce with the continuous increasing production. Finally, from Figures 9 and 13, it can be seen that water flooding time will be later with the increasing injection-production ratio.

3.3.2. Water Injection Rate Is Equal to Production. Respectively, give the final computed time of pore pressure contours, $Z$-direction displacement contours of the block, and the change curve with time about pore pressure of the 


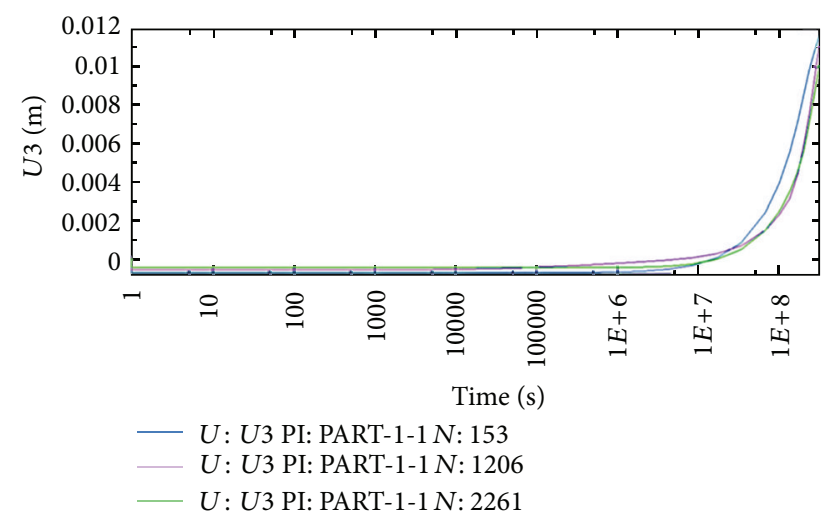

Figure 6: The change curve with time about $Z$-direction displacement of the three points when injection-production ratio is $1: 0$.

POR $(\mathrm{Pa})$

(Avg: 75\%)
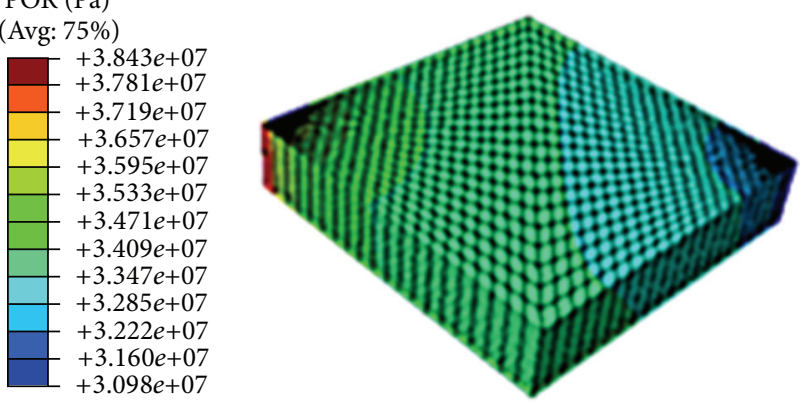

Figure 7: Pore pressure contours of the block when injectionproduction ratio is $1: 0.5$.
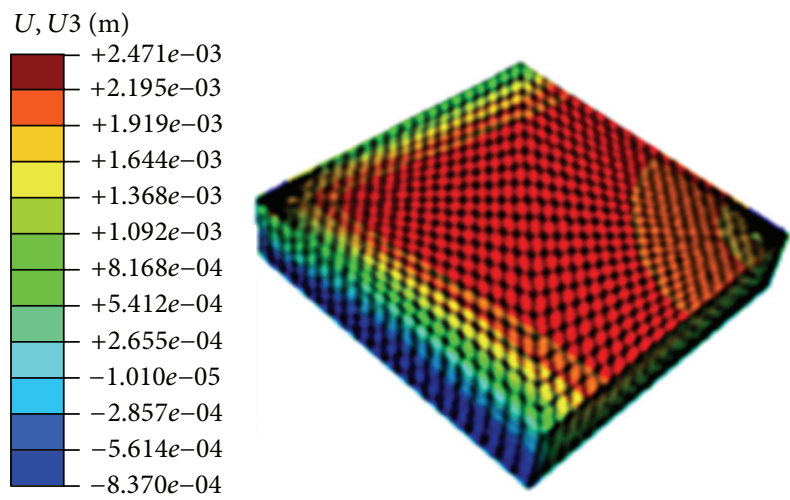

FIGURE 8: $Z$-direction displacement contours of block when injection-production ratio is $1: 0.5$.

three points (N1206, N2261, and N153), when the injectionproduction ratio is $1: 1$. They are shown in Figures 15, 16, 17, and 18.

First of all, from Figure 15, we can find that when the injection ratio is $1: 1$, pore pressure near the injection well of the simulation has an upward trend, but pore pressure near the production well has a slight decrease. What is more, from Figure 17, pore pressure near the production well firstly

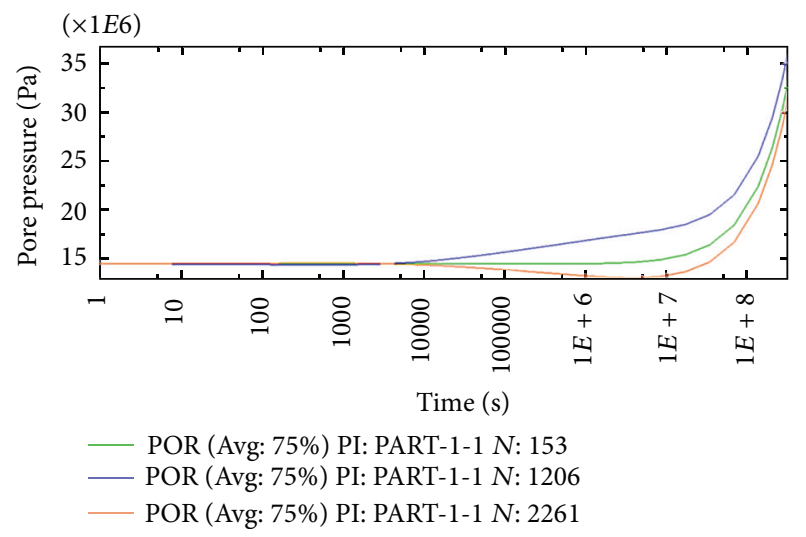

FIGURE 9: The change curve with time about pore pressure of the three points when injection-production ratio is $1: 0.5$.

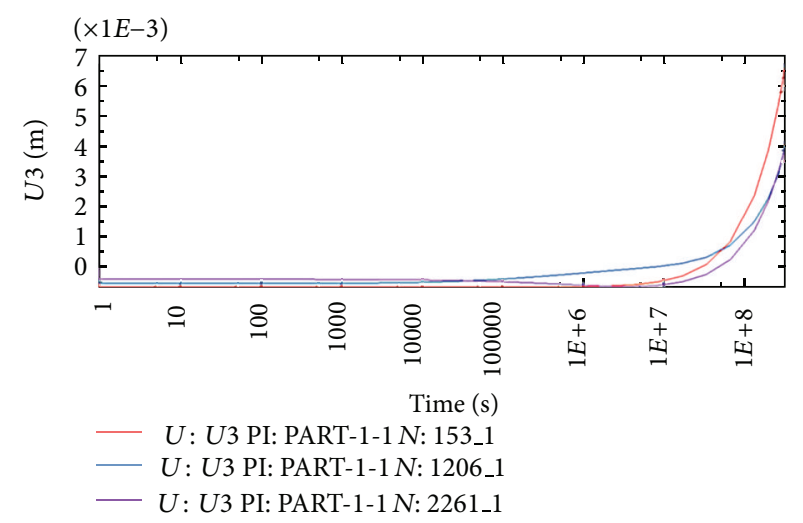

FIgure 10: The change curve with time about $Z$-direction displacement of the three points when injection-production ratio is $1: 0.5$.
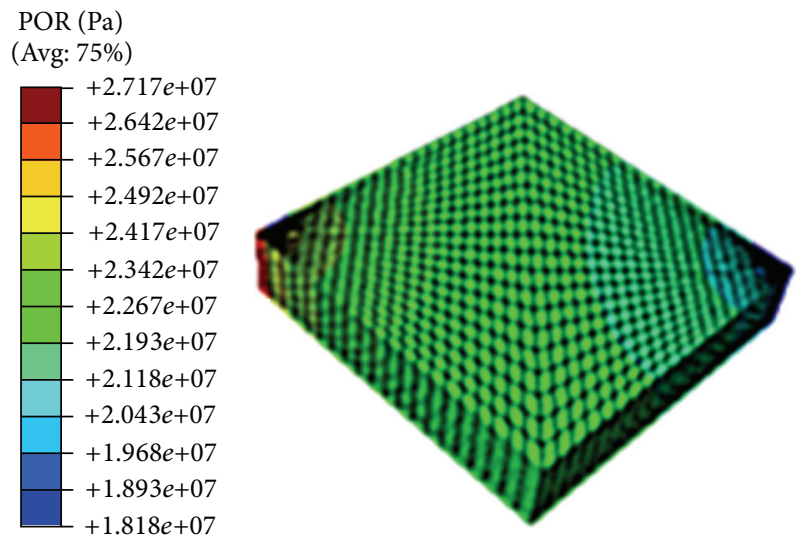

Figure 11: Pore pressure contours of the block when injectionproduction ratio is $1: 0.8$.

increases and then remains unchanged, while pore pressure near the production well firstly decreases and then remains unchanged, and pore pressure of the midpoint between injection well and oil well remains basically unchanged. 

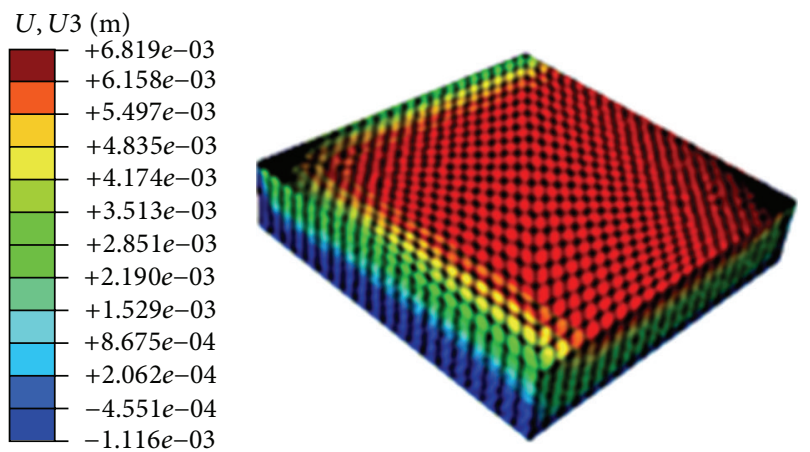

FIGURE 12: $Z$-direction displacement contours of block when injection-production ratio is $1: 0.8$.

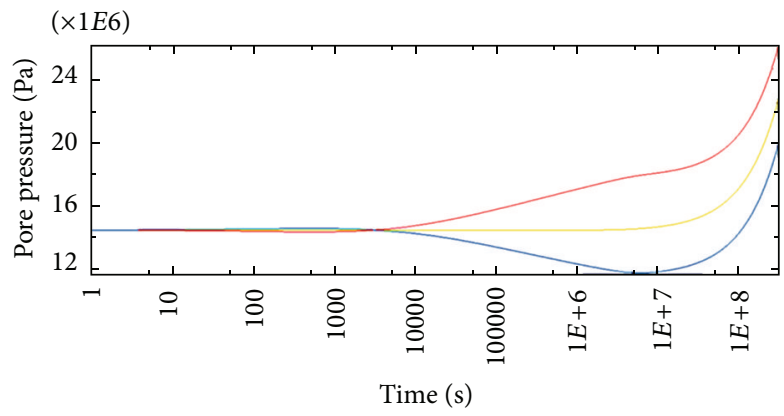

POR (Avg: 75\%) PI: PART-1-1 N: 153

- POR (Avg: 75\%) PI: PART-1-1 N: 1206

— POR (Avg: 75\%) PI: PART-1-1 N: 2261

FIGURE 13: The change curve with time about pore pressure of the three points when injection-production ratio is $1: 0.8$.

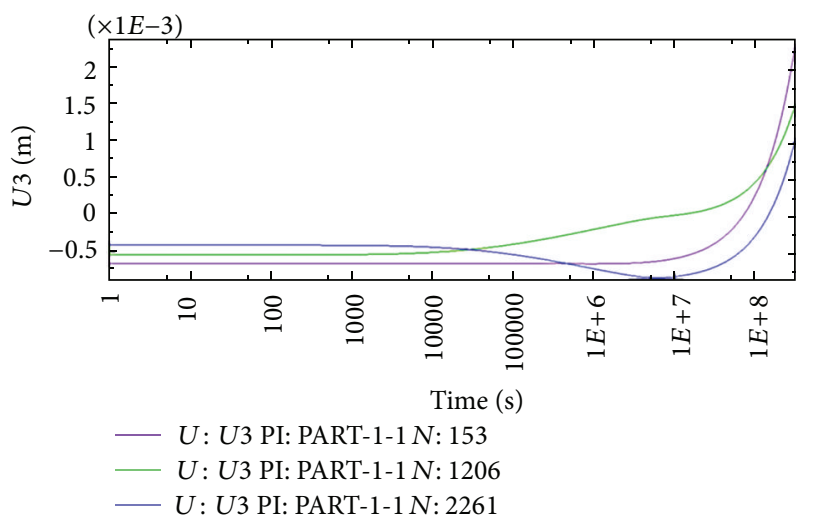

FIgURE 14: The change curve with time about $Z$-direction displacement of the three points when injection-production ratio is $1: 0.8$.

Finally, from Figure 18, it can be seen that the upper surface of the block rock mass near the injection well of the simulation has a positive displacement in the $Z$-direction due to the increase of pore pressure and the decrease of effective stress while near the production well of the simulation has a
POR $(\mathrm{Pa})$

(Avg: 75\%)
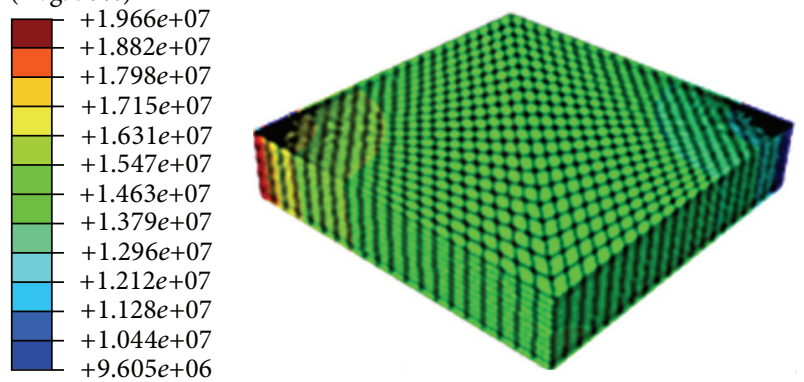

Figure 15: Pore pressure contours of the block when injectionproduction ratio is $1: 1$.
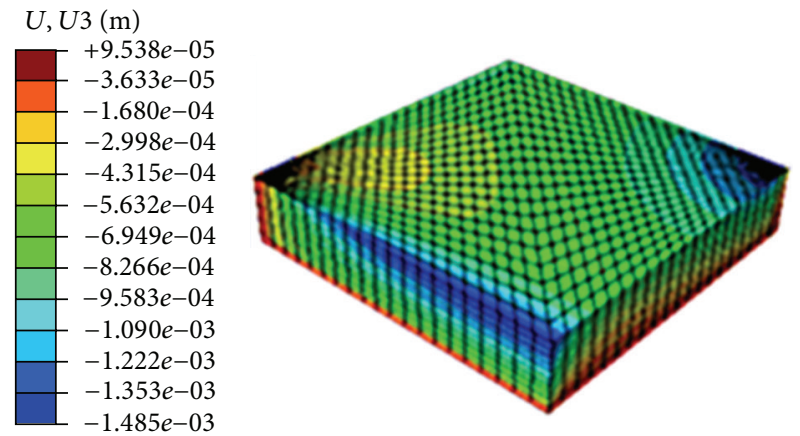

FIGURE 16: Z-direction displacement contours of block when injection-production ratio is $1: 1$.

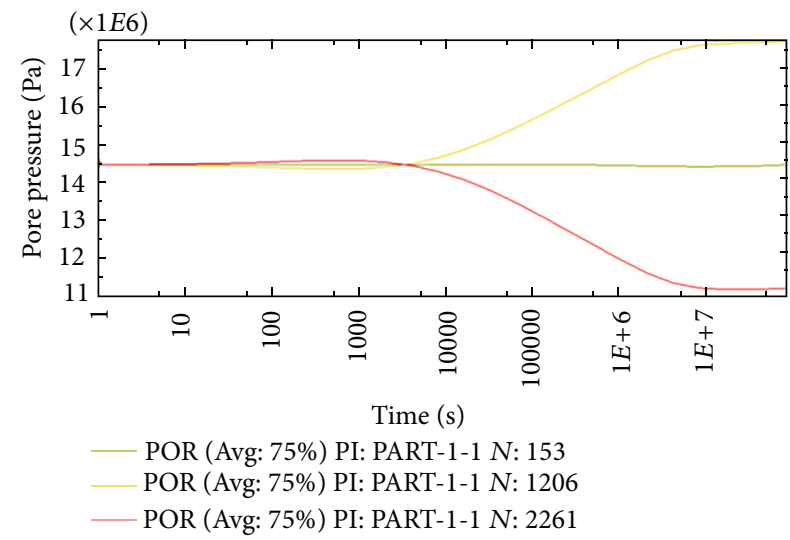

FIGURE 17: The change curve with time about pore pressure of the three points when injection-production ratio is $1: 1$.

negative displacement in the $Z$-direction due to the decrease of pore pressure and the increase of effective stress.

3.3.3. Water Injection Rate Is Less Than the Production. According to the injection-production ratio: $1: 1.2 ; 1: 1.5 ; 1: 1.8$, respectively, give the final computed time of pore pressure contours, $Z$-direction displacement contours of the block, and the change curve with time about pore pressure of the 


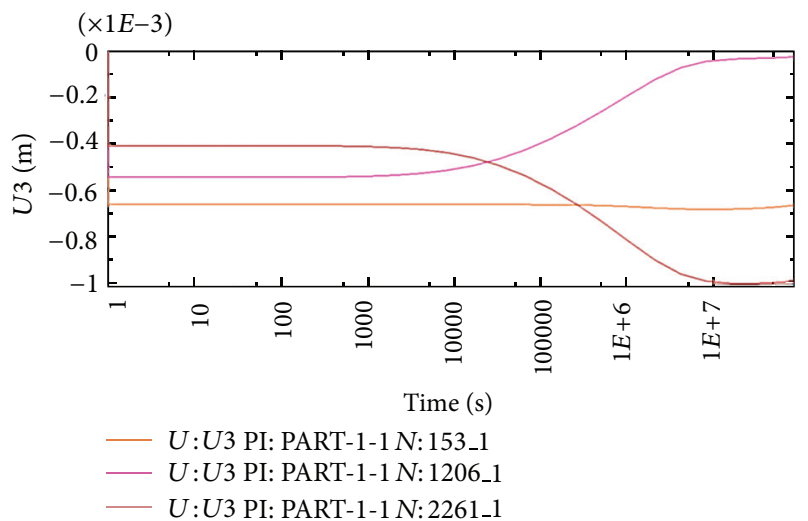

FIgURE 18: The change curve with time about $Z$-direction displacement of the three points when injection-production ratio is $1: 1$.
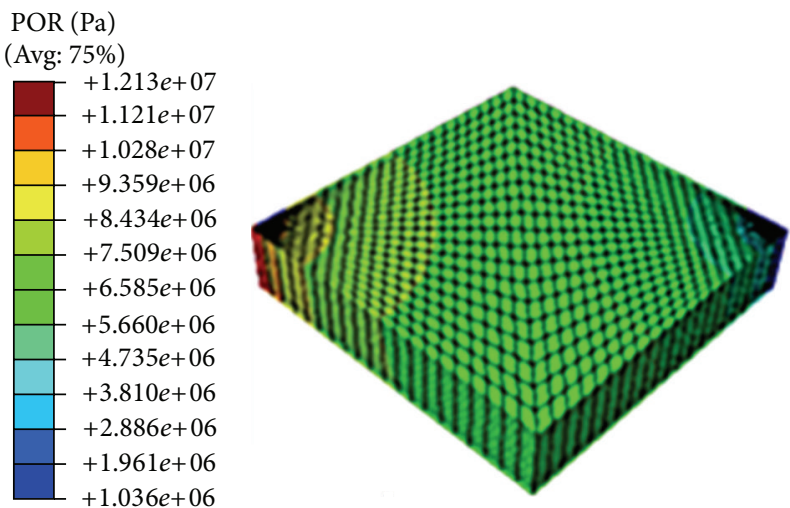

FIGURE 19: Pore pressure contours of the block when injectionproduction ratio is $1: 1.2$.
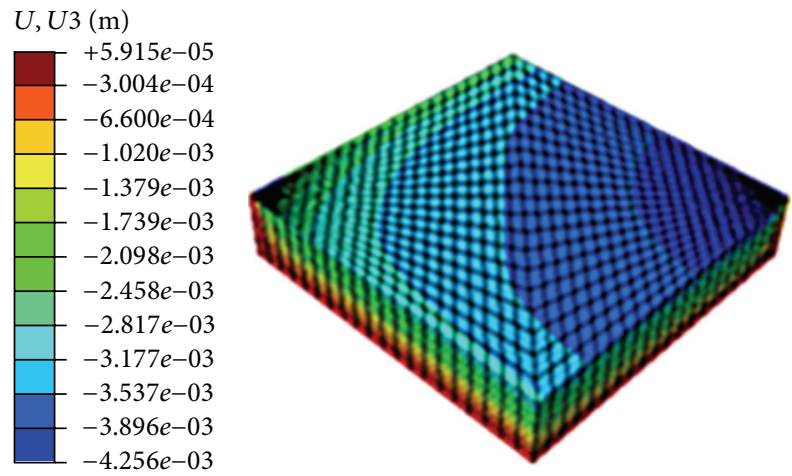

FIGURE 20: $Z$-direction displacement contours of block when injection-production ratio is $1: 1.2$.

three points (N1206, N2261, and N153). They are shown in Figures 19-30.

From Figure 19, it can be seen that pore pressure of the entire block of the simulation becomes lower than the formation pore pressure (14.5 $\mathrm{MPa})$, and pore pressure near the injection well is smaller than the pore pressure near

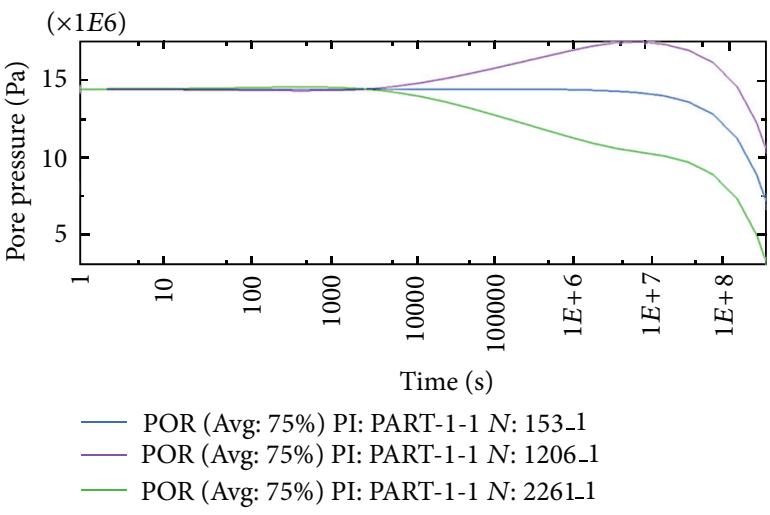

FIgURE 21: The change curve with time about pore pressure of the three points when injection-production ratio is $1: 1.2$.

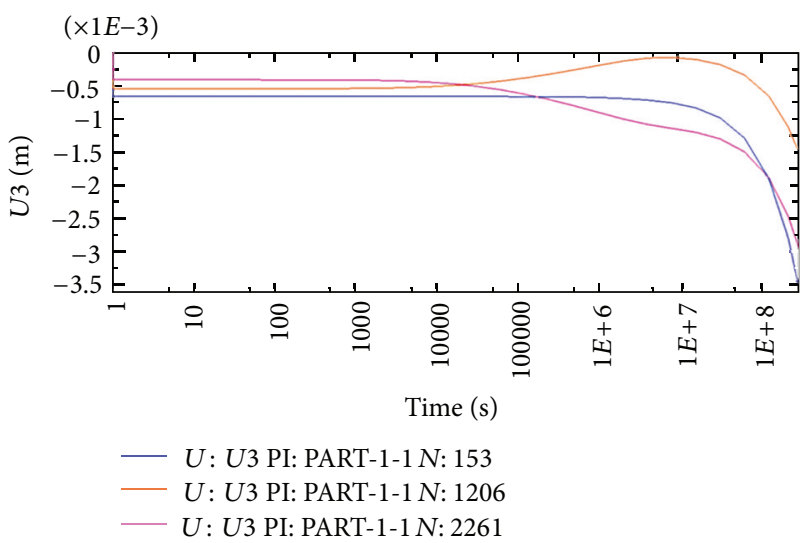

FIGURE 22: The change curve with time about $Z$-direction displacement of the three points when injection-production ratio is $1: 1.2$.

POR $(\mathrm{Pa})$

(Avg: $75 \%)$

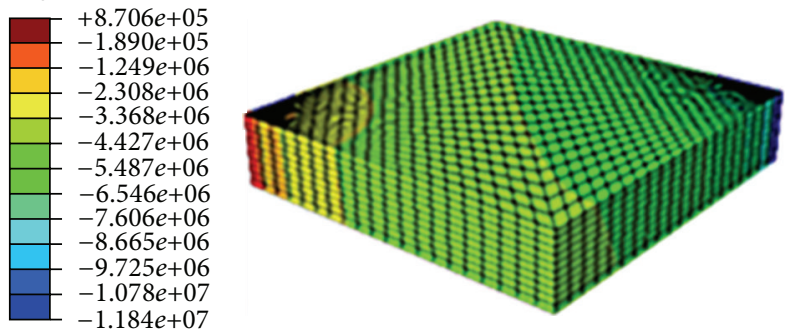

FIGURE 23: Pore pressure contours of the block when injectionproduction ratio is $1: 1.5$.

production well. What is more, from Figure 20, we can find that the upper surface of the block rock mass of the simulation has a negative displacement in the $Z$-direction. Finally, from Figures 21 and 22, we can get the conclusions that pore pressure and $Z$-direction displacement near the injection well firstly increase and then remain decreasing, and the start time of reducing is about the 115.7 th day, while pore pressure and 
$U, U 3(\mathrm{~m})$
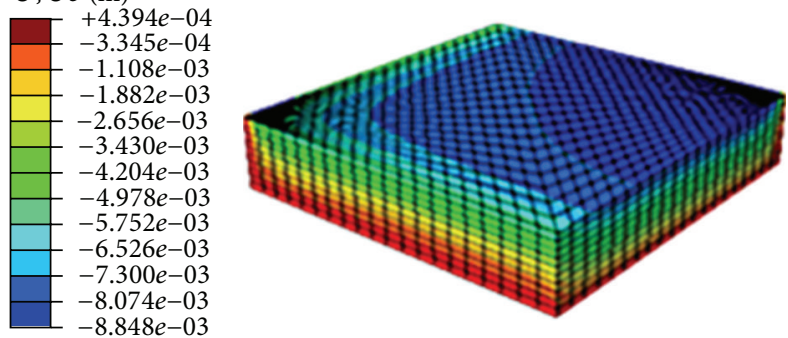

FIGURE 24: Z-direction displacement contours of block when injection-production ratio is $1: 1.5$.

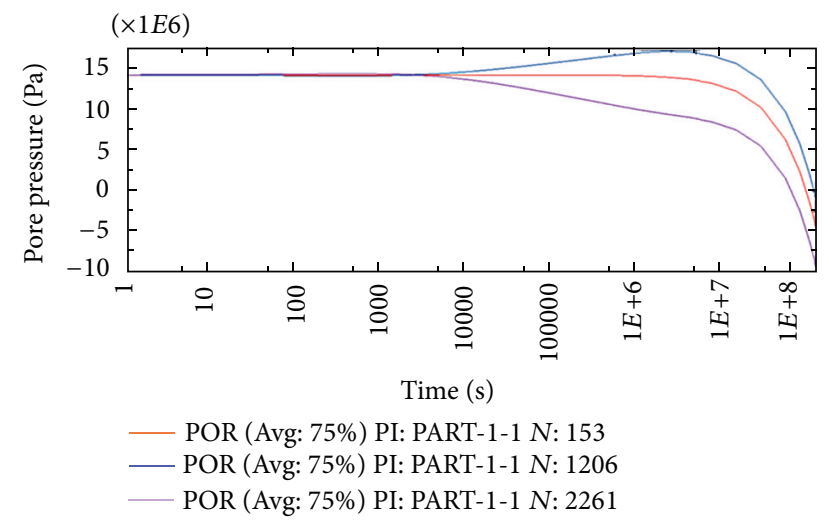

FIGURE 25: The change curve with time about pore pressure of the three points when injection-production ratio is $1: 1.5$.

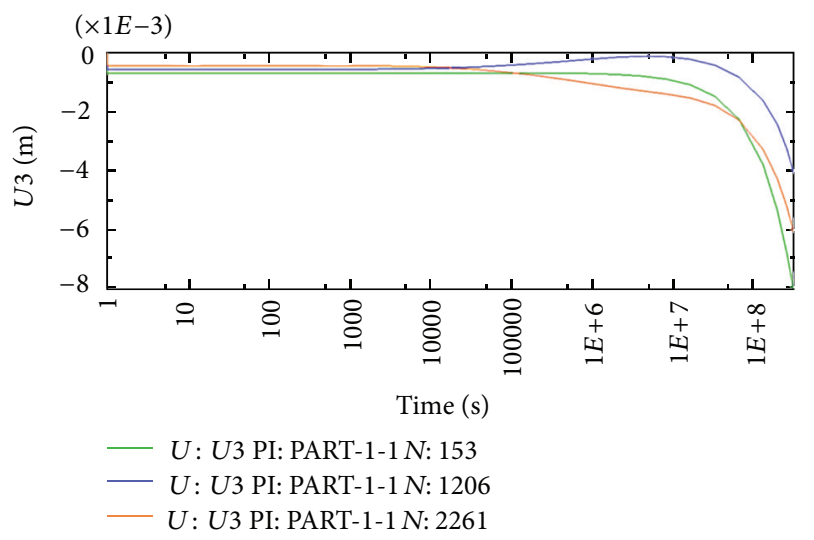

Figure 26: The change curve with time about $Z$-direction displacement of the three points when injection-production ratio is $1: 1.5$.

$Z$-direction displacement near the production well remain decreasing with time increasing.

From Figure 23, it can be seen that pore pressure of the entire block of the simulation becomes much lower than the formation pore pressure (14.5 MPa), and pore pressure near the injection well is smaller than pore pressure near production well. And the place near production well is in the vacuum; certainly this is just the numerical simulation results. What is more, from Figure 24, we can find that the
POR $(\mathrm{Pa})$

(Avg: $75 \%)$
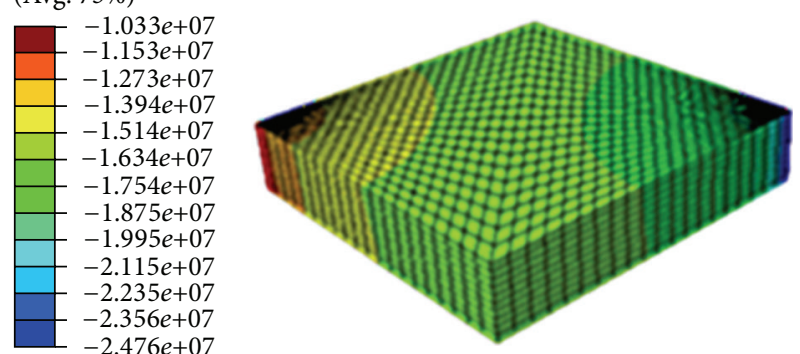

Figure 27: Pore pressure contours of the block when injectionproduction ratio is $1: 1.8$.
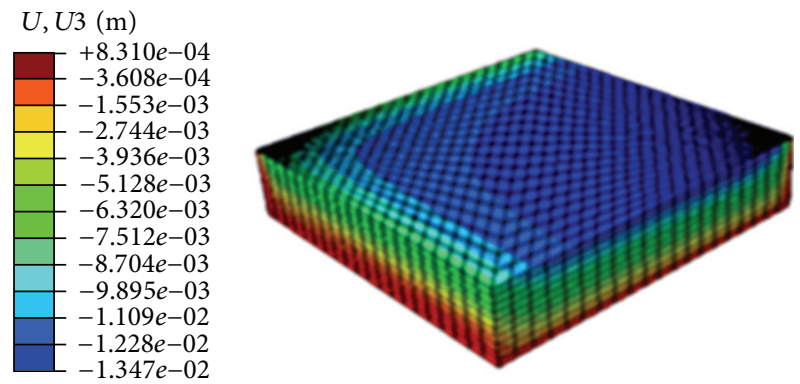

FIGURE 28: Z-direction displacement contours of block when injection-production ratio is $1: 1.8$.

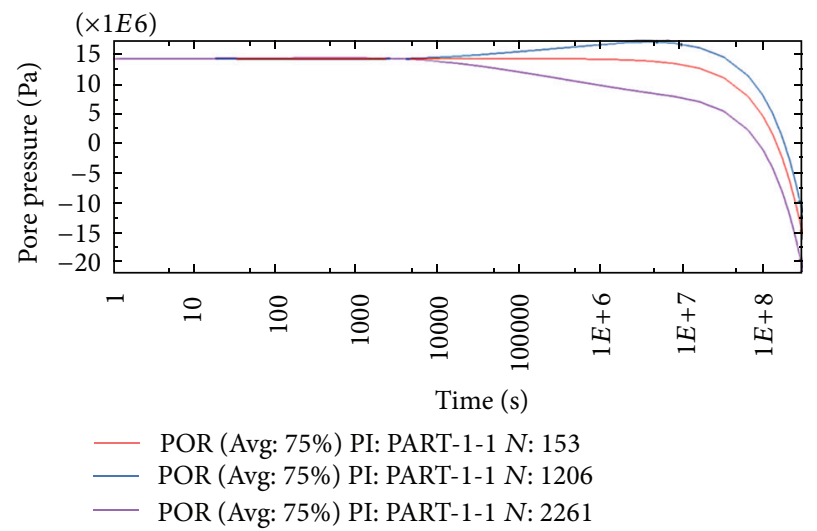

FIGURE 29: The change curve with time about pore pressure of the three points when injection-production ratio is $1: 1.8$.

upper surface of the block rock mass of the simulation has a negative displacement in the $Z$-direction. Finally, from Figures 25 and 26 , we can get the conclusions that pore pressure and $Z$-direction displacement near the injection well firstly increase and then remain decreasing, and the start time of reducing is about the 57.9th day, while pore pressure and $Z$-direction displacement near the production well remain decreasing with time increasing.

From Figure 27, it can be seen that pore pressure of the entire block of the simulation becomes much lower than the formation pore pressure $(14.5 \mathrm{MPa})$, and pore pressure 


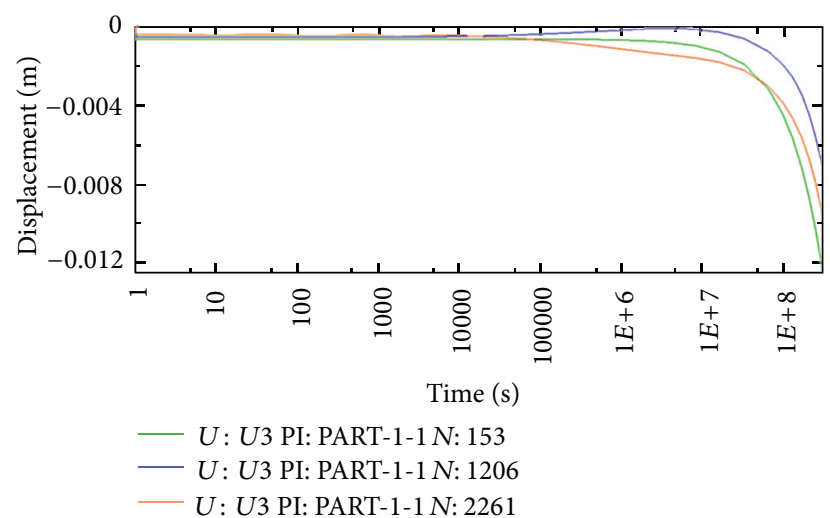

FIgURE 30: The change curve with time about $Z$-direction displacement of the three points when injection-production ratio is $1: 1.8$.

near the injection well is smaller than pore pressure near production well. And the place near production well is in the vacuum; certainly this is just the numerical simulation results. What is more, from Figure 28, we can find that the upper surface of the block rock mass of the simulation has a negative displacement in the $Z$-direction. Finally, from Figures 29 and 30, we can get the conclusions that pore pressure and $Z$-direction displacement near the injection well firstly increase and then remain decreasing, and the start time of reducing is about the 35.3th day, while pore pressure and $Z$-direction displacement near the production well remain decreasing with time increasing.

Firstly, from the comparison to Figures 19, 23, and 27, it can be seen that when the water injection rate is smaller than production and water injection rate is fixed, pore pressure of the entire block presents a continuous greatly decreasing trend with the injection-production ratio increasing. Secondly, from Figures 20, 24, and 28, we can find that the negative $Z$-direction displacement of entire block continues to become larger with the continuous increasing production. Finally, from Figures 21, 25, and 29, it can be seen that pore pressure near injection well advances with the increasing injection-production ratio.

\section{Conclusions}

Using the FEM Software ABAQUS, through numerical simulation, from the simulation results, we can get the following conclusions.

(1) When water injection rate is more than production, we can find that pore pressure near the injection well shows a tendency to continuously increase with time; however, pore pressure near the production well firstly decreases and then increases. And it can be seen that water flooding time will be more and more late with the increasing of the injection-production ratio.

(2) When water injection rate is equal to production, pore pressure near the injection well of the simulation has an upward trend, but pore pressure near the production well has a slight decrease. And pore pressure near the production well firstly increases and then remains unchanged, while pore pressure near the production well firstly decreases and then remains unchanged, and pore pressure of the midpoint between injection well and oil well remains basically unchanged. It can be easily seen that the upper surface of the block rock mass near the injection well of the simulation has a positive displacement in the $Z$-direction due to the increase of pore pressure and the decrease of effective stress, while near the production well of the simulation has a negative displacement in the $Z$ direction due to the decrease of pore pressure and the increase of effective stress.

(3) When water injection rate is less than the production, it can be seen that pore pressure of the entire block of the simulation becomes much lower than the formation pore pressure. For example, when injectionproduction ratio is $1: 1.8$, the minimum pore pressure of the sidewall of oil well reaches $-17.88 \mathrm{MPa}$ and the largest settlement of strata reaches $-16.55 \mathrm{~mm}$.

(4) For the entire area of the study, with the injection ratio increasing, pore pressure of block rock gradually decreases and along the negative $Z$-direction displacement gradually increases; with injectionproduction ratio ranging from $1: 0$ to $1: 1.8$, pore pressure of the sidewall of injection well decreases from $+50.88 \mathrm{MPa}$ to $-17.88 \mathrm{MPa}$ and the displacement of stratum surface decreases from $+13.00 \mathrm{~mm}$ to $-16.55 \mathrm{~mm}$, which is consistent with the actual situation.

\section{Acknowledgments}

This paper is financially supported by Natural Science Foundation of China (Grant no. 51174170) and National Science and Technology Major Project of China under Grant no. 2011ZX05013-006.

\section{References}

[1] M. S. Bruno and F. M. Nakagawa, "Bore pressure influence on tensile fracture propagation in sedimentary rock," International Journal of Rock Mechanics and Mining Sciences and, vol. 28, no. 4, pp. 261-273, 1991.

[2] J. L. Elbel and M. G. Mack, "Refracturing: observations and theories," in Proceedings of the Production Operations Symposium, pp. 521-531, March 1993.

[3] R. L. Johnson and J. L. Rodgerson, "More effective hydraulic fracturing in secondary, in-fill developments, Permian Basin, using bottomhole pressure and in-situ stress profiling techniques," in Proceedings of the SPE Permian Basin Oil \& Gas Recovery Conference, pp. 281-296, March 1998.

[4] N. R. Warplnskl and P. T. Branagan, "Altered-stress fracturing," Journal of Petroleum Technology, vol. 41, no. 9, pp. 990-997, 1989.

[5] J. J. Liu and G. H. Pei, "Fiuid-Soild Coupling Simulation of Fractured Low Permeability Oil Reservoir," http://www.paper .edu.cn/.

[6] X. P. Fan, X. R. Xu, and S. C. Zhang, "Analysis on changes of stress, strain, porosity and permeability in multiphase reservoir 
with fluid-solid coupled and geomechanical mathematic simulation," Rock and Soil Mechanics, vol. 22, no. 1, pp. 47-50, 2001.

[7] Z. M. Yin, Q. Wu, J. J. Liu, and C. H. Yang, "Numerical simulation of geo-stress distribution during injecting well blowout," Rock and Soil Mechanics, vol. 25, no. 3, pp. 363-368, 2004.

[8] D. M. Wang and G. M. Wu, "Formation pressure calculation model and its field application," Daqing Petroleum Geology and Development, vol. 26, no. 4, pp. 84-87, 2007.

[9] N. L. Xiu, G. R. Tian, Y. Z. Yan, and X. M. Yan, "The effect of water injection on horizontal terrestrial stress in low permeability reservoirs," Special Oil and Gas Reservoirs, vol. 16, no. 2, pp. 53-55, 2009.

[10] J. J. Liu and X. B. Yu, "Stress analysis on the combination of casing- cement ring -surrounding rock considering fluid-solid coupling," Electronic Journal of Geotechnical Engineering, vol. 17, pp. 1863-1873, 2012.

[11] J. J. Liu, C. H. Yang, and Z. M. Yin, "Study on seepage field during injection well releasing pressure and its effect on casing damage," Journal of University of Science and Technology of China, vol. 34, no. zl, pp. 155-160, 2004.

[12] J. J. Liu, X. G. Liu, Y. R. Hu et al., "Study of fluid-solid coupling flow in low permeablable oil reservoir," Chinese Journal of Rock Mechanics and Engineering, vol. 21, no. 1, pp. 48-54, 2002.

[13] W. Chen, W. Wu, and J. Shanpo, The application of ABAQUS in the tunnel engineering and underground engineering, China Water Conservancy and Electricity Press, Beijing, China, 2010.

[14] X. L. Huang, H. J. Mao, J. J. Liu, C. H. Yang, J. Xiong, and H. Zhou, "Application of ANSYS in forecasting of water injection well casing damage," Chinese Journal of Rock Mechanics and Engineering, vol. 24, no. z1, pp. 5146-5150, 2005. 


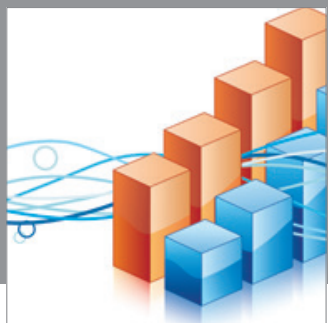

Advances in

Operations Research

mansans

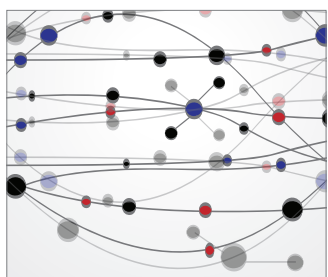

The Scientific World Journal
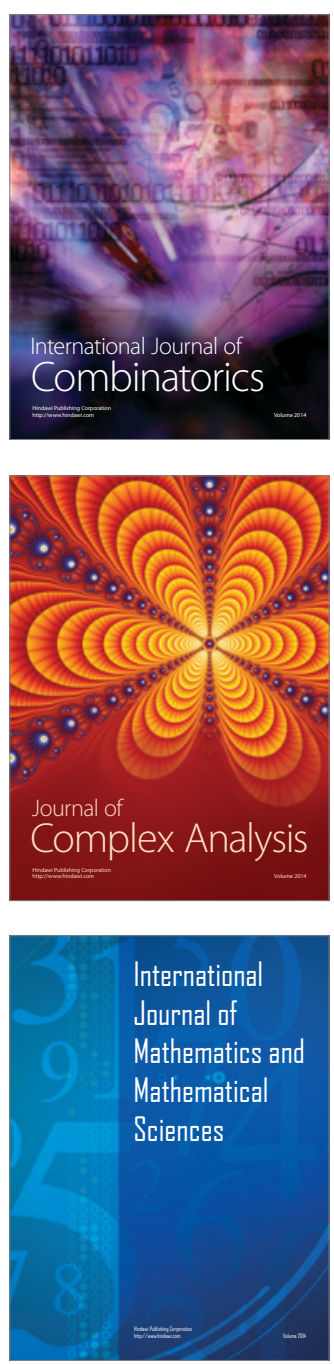
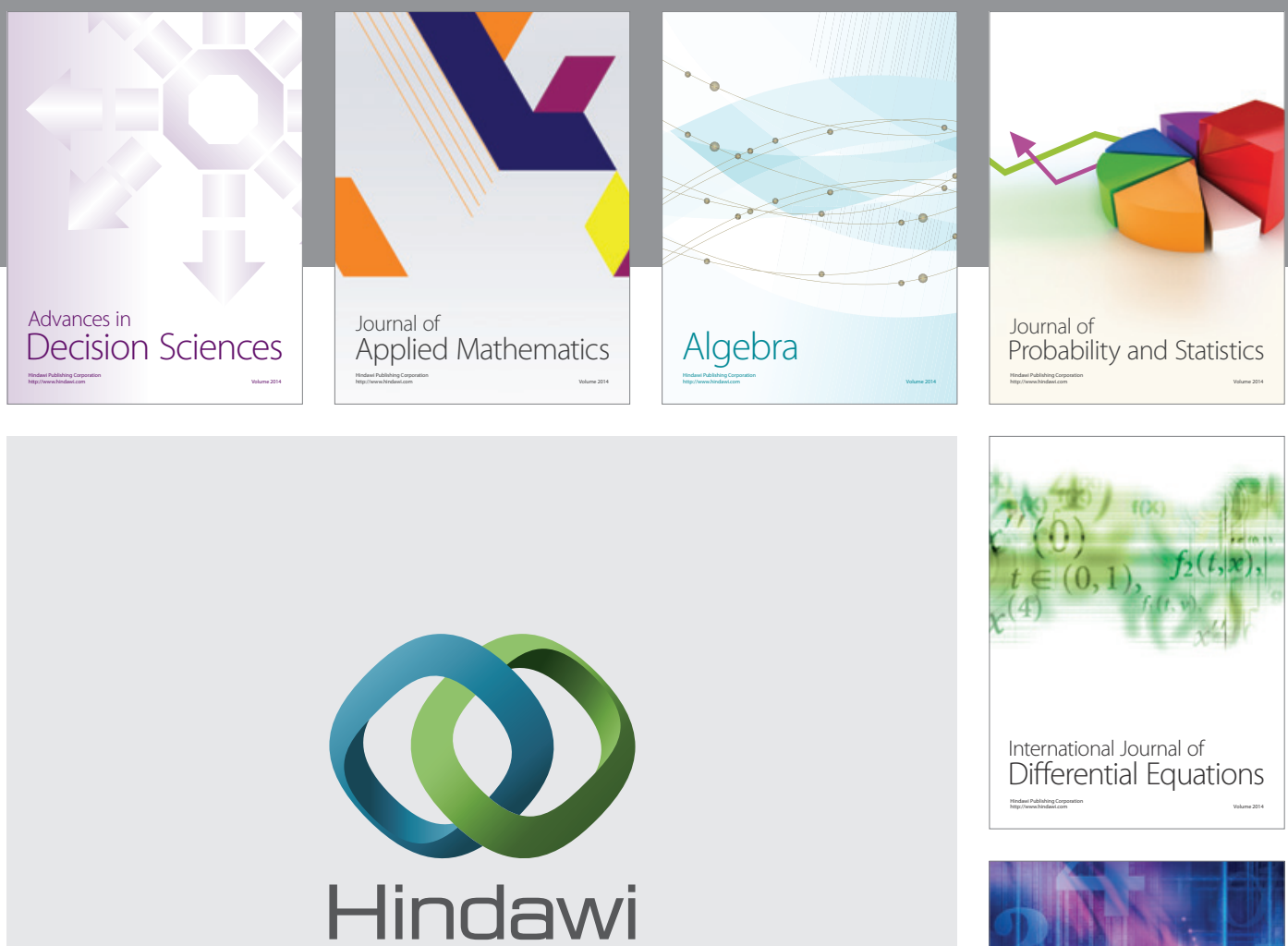

Submit your manuscripts at http://www.hindawi.com
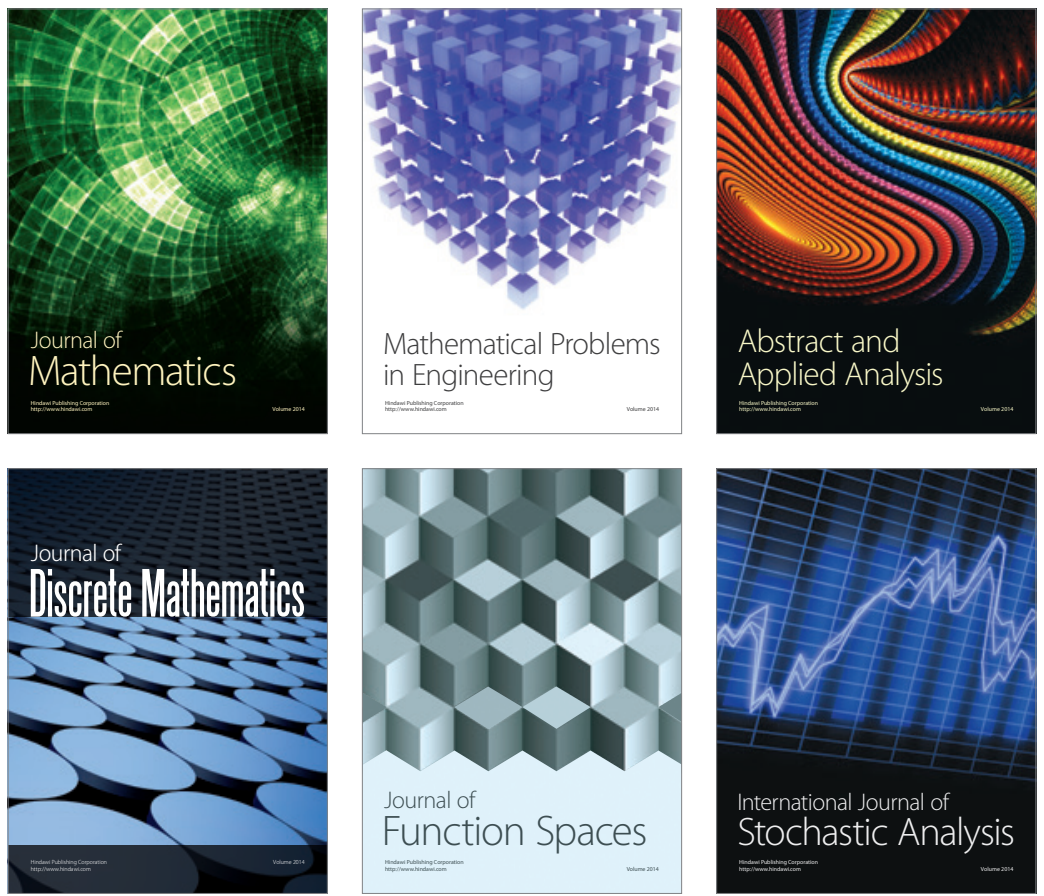

Journal of

Function Spaces

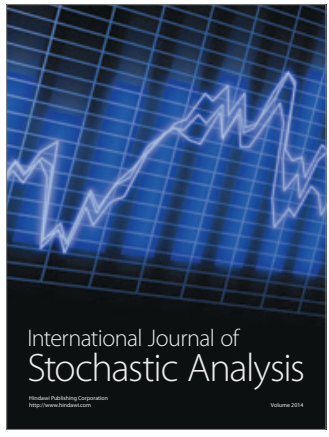

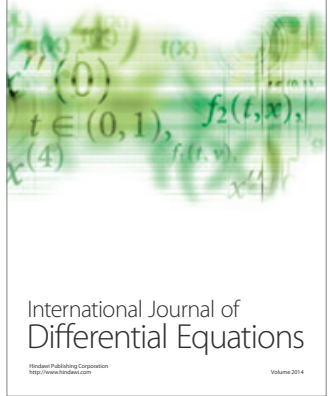
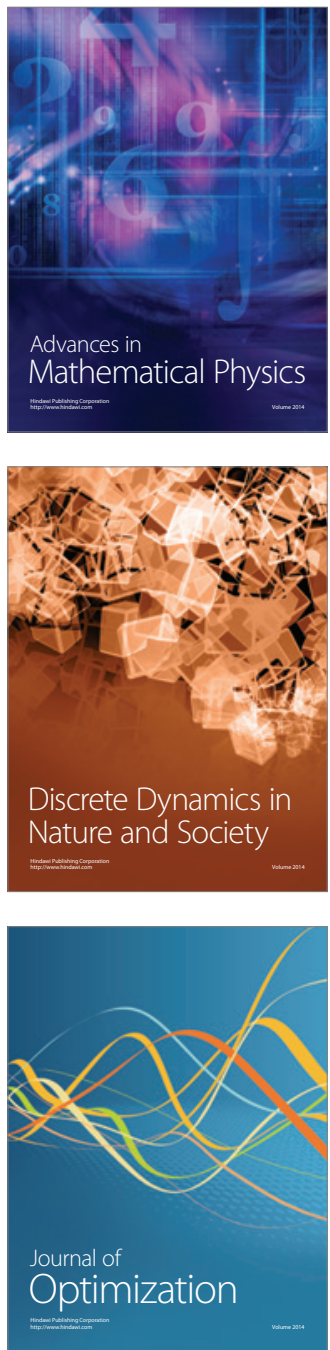